\section{Post-tetanic burst count: a stimulating pattern for profound neuromuscular blockade}

Yuhji Saitoh MD, Yoshitaka Fujii MD,

Hidenori Toyooka MD, Keisuke Amaha MD
The purpose of this study was to compare the pattern of recovery from vecuronium $0.07 \mathrm{mg} \cdot \mathrm{kg}^{-1}$ induced neuromuscular blockade using post-tetanic burst count (PTBC) - (three short tetanic bursts of $0.2 \mathrm{msec}$ duration every $20 \mathrm{msec}$ given every second following a tetanus), and post-tetanic count (PTC) (0.2 msec single twitch stimuli given every second following a tetamus) using an accelerometer in 60 actult patients during nitrous oxide-oxygen-isoflurane anaesthesia. In addition, the relationship among $P T B C, P T C$, and $T_{1}$ (the lst response in the train-of-four (TOF) stimulation) was examined to investigate whether the PTBC had an advantage over the PTC or TOF for evaluating intense neuromuscular blockade. The PTBC was greater than PTC during the 15-35 min after the administration of vecuronium (unpaired $t$ test with Bonferroni's correction, $P<0.05$ ). Time to the return of $P T B$ response was shorter than that of $P T T$ (17.7 \pm 3.2 vs $22.7 \pm 3.7 \mathrm{~min}$, unpaired $t$ test, $P=0.0005$ ). Time from the return of PTB to that of $T_{1}$ was longer than the time from the return of $P T C$ to that of $T_{1}$ (13.3 \pm 2.6 vs $9.2 \pm 2.8 \mathrm{~min}$, unpaired t test, $P=0.0003)$. At the return of $T_{1}, P T B C$ was greater than PTC (14.3 \pm 6.9 vs $9.4 \pm 2.3$, unpaired $t$ test, $P=0.0153)$. These results suggest that, using PTBC, a more profound level of neuromuscular blockade can be evaluated than that using PTC.

Key words

MONITORING: neuromuscular junction;

NEUROMUSCULAR RELAXANTS: vecuronium.

From the Department of Anesthesiology and Critical Care Medicine, Faculty of Medicine, Tokyo Medical and Dental University, Tokyo, Japan and *Department of Anesthesiology, Toride Kyodo General Hospital, Ibaraki, Japan.

Address correspondence to: Dr. Y. Saitoh, Department of Anesthesiology and Critical Care Medicine, Faculty of Medicine, Tokyo Medical and Dental University, 5-45, Yushima, 1-Chome, Bunkyo-ku, Tokyo 113, Japan.

Accepted for publication 11th August, 1995.
Cette étude visait à comparer, après curarisation au vécuronium $0,7 \mathrm{mg} \cdot \mathrm{kg}^{-1}$, le pattern de la décurarisation avec le compte du burst past-tétanique (PTBC - trois courtes salves de tétanos de 0,2 sec aux 20 msec à toutes les secondes après un tétanos) avec celui du compte post-tétanique (PTC - un twitch simple de 0,2 msec à toutes les secondes après un tétanos). L'accélérométrie a été utilisé chez 60 patients adultes pendant une anesthésie à l'association $\mathrm{N}_{2} \mathrm{O}$-oxygène-isoflurane. En outre, la relation entre PTBC, $P T C$ et $T_{1}$ (la première résponse du TOF) a été étudiée pour savoir si le PTBC avait un avantage sur le PTC ou le TOF pour évaluer la curarisation profonde. La PTBC a été supérieur au PTC et au TOF pendant les 15 à 35 min qui ont suivi l'administration de vécuronium (test $T$ non pairé avec correction de Bonferroni, $P<0,05$ ). Lintervalle précédant le retour du PTB a été plus court que celui du PTT (17,7 $\pm 3,2$ vs 22,7 $\pm 3,7 \mathrm{~min}$, test $T$ non apparié, $P=0,0005)$. Lintervalle précédant le retour du PTB à celui du $T_{l}$ a été plus long que celui du retour du PTC à celui du $T_{1}(13,3$ $\pm 2,6$ vs 9,2 $\pm 2,8 \mathrm{~min}$, test $T$ non apparié, $P=0,0003)$. Au retour du $T_{1}$, le PTBC a été plus grand que le PTC $(14,3$ $\pm 6,9$ vs $9,4 \pm 2,3 T$ non apparié, $P=0,0153$ ). Ces résultats suggèrent que, avec le PTBC, un niveau plus profond de curarisation peut être évalué qu'avec le PTC.

Recently we reported a new monitoring method for profound neuromuscular blockade - post-tetanic burst (PTB) ${ }^{1}$ which consists of a tetanus, a pause, and one burst stimulus. Using PTB more profound neuromuscular blockade can be detected than using post-tetanic twitch (PTT). In clinical practice a large dose of short or intermediate acting neuromuscular relaxant is often administered so that intense neuromuscular blockade subsides rapidly. From this viewpoint, the PTB is useful in evaluating such intense neuromuscular blockade. However, in the previous report evaluation of profound neuromuscular blockade was incomplete because the PTB produced, at most, only single muscular contraction following tetanus. We assumed that it would be of clinical importance to grade such profound neuromuscular block- 
ade by its intensity and to establish the relationship between the new monitoring method for intense neuromuscular blockade and the traditional methods, i.e., posttetanic count (PTC) and train-of-four (TOF). Therefore, in this study, burst stimuli were given every second for $30 \mathrm{sec}$ after a tetanus during recovery from vecuroniuminduced neuromuscular blockade and the number of detectable muscular contractions to the burst stimuli (posttetanic burst count, PTBC) was recorded. Recovery of the response to single twitch stimulation following tetanus, PTC, was also measured, and compared with that of PTBC. Further, the relationship among PTBC, PTC, and $T_{1}$ (the 1st response in TOF stimulation) was studied.

\section{Methods}

Sixty adult patients (28 male and 32 female), ASA physical status 1-2, scheduled for elective general anaesthesia were studied. Patients with neuromuscular, metabolic, hepatic or renal disorder, and those receiving drugs known to affect the action of neuromuscular relaxants were excluded. The patients gave their informed consent to the protocol, which was approved by the local clinical investigation committee.

The patients were assigned randomly to four groups: post-tetanic burst count (PTBC) group $(n=15)$, posttetanic count (PTC) group $(n=15)$, post-tetanic burst count-train of four (PTBC-TOF) group $(n=15)$, or posttetanic count-train of four (PTC-TOF) group $(n=15)$. Premedication of atropine $0.01 \mathrm{mg} \cdot \mathrm{kg}^{-1}$ and hydroxyzine $1.0 \mathrm{mg} \cdot \mathrm{kg}^{-1}$ im was administered $30 \mathrm{~min}$ before induction of anaesthesia. In the operating room two stimulating surface electrodes (Vitrode, M-150, NihonKohden Inc., Tokyo, Japan) were placed over the ulnar nerve of the forearm contralateral to the blood pressure cuff. The distal electrode (negative) was placed about 1 $\mathrm{cm}$ proximal to the point where the proximal flexion crease of the wrist crossed the radial side of the tendon to the ulnar flexor carpi muscle, and the proximal electrode (positive) was placed $2-3 \mathrm{~cm}$ proximal to the distal electrode. An acceleration transducer (Accelograph, Biometer International, Odense, Denmark) was fastened to the volar side of the interphalangeal joint of the corresponding thumb to measure the acceleration of the thumb adduction resulting from contraction of the adductor pollicis muscle. Anaesthesia was induced with thiopentone $5.0 \mathrm{mg} \cdot \mathrm{kg}^{-1}$ and tracheal intubation was facilitated with succinylcholine $1.0 \mathrm{mg} \cdot \mathrm{kg}^{-1} \dot{i}$. Anaesthesia was maintained with isoflurane, $1.0 \%$ end-tidal, and nitrous oxide $66 \%$ in oxygen. Patients' lungs were ventilated to maintain normocapnia. The concentrations of nitrous oxide, oxygen, carbon dioxide, and isoflurane were measured continuously using a multiple gas analyser (CapnomacUltima, S-31-03, Datex, Inc., Helsinki, Finland). The peripheral skin temperature of the investigated arm was measured using a thermometer (Terumo-Finer, CTM303, Terumo, Tokyo, Japan).

In each group, single twitch stimuli of $0.2 \mathrm{msec}-$ duration were delivered every $15 \mathrm{sec}$ at $50 \mathrm{~mA}$ using an electrical stimulator (Isolator, SEN-3201, NihonKohden Inc., Tokyo, Japan). The corresponding accelographic values of the contraction of the thumb in response to the single stimuli were measured and recorded on the strip-chart recorder of a neuromuscular transmission analyser (Myograph 2000, Biometer International, Odense, Denmark) at a chart speed of $1 \mathrm{~mm} \cdot \mathrm{sec}^{-1}$. When the evoked responses to single twitch stimuli became stable, approximately $20 \mathrm{~min}$ after the administration of succinylcholine, the evoked response to single stimulation was taken as the control value. Vecuronium $0.07 \mathrm{mg} \cdot \mathrm{kg}^{-1}$ was then administered.

In the PTBC group, post-tetanic burst (PTB) stimulation, which consisted of a $50 \mathrm{~Hz}$ tetanic stimulation of five seconds, a pause of three seconds, and $50 \mathrm{~Hz}$ burst stimuli given every second for $30 \mathrm{sec}$, was repeated at $50 \mathrm{~mA}$ every five minutes after the administration of vecuronium. Each burst consisted of three impulses, each of 0.2 msec-duration, every $20 \mathrm{msec}$. In the PTC group, post-tetanic twitch (PTT) stimulation, which consisted of a five seconds tetanus, a three seconds pause, and one $\mathrm{Hz}$ single twitch stimuli of 0.2 msec-duration applied for $30 \mathrm{sec}$, was delivered at $50 \mathrm{~mA}$ every five minutes. The accelographic values of the contraction of the thumb in response to PTB, PTT, and TOF stimuli were also quantified and recorded on the strip-chart recorder at a chart speed of $1 \mathrm{~mm} \cdot \mathrm{sec}^{-1}$. The number of detectable responses to burst or single twitch stimuli following a tetanus were counted on the recording chart and were reganded as post-tetanic burst count (PTBC) or post-tetanic count (PTC).

In the PTBC-TOF and PTC-TOF groups, PTBC or PTC was measured every five minutes until the return of PTB or PTT response so that the time from the administration of vecuronium to the return of PTB or PTT response was determined. One minute after the return of PTB or PTT, the stimulation pattern was changed to TOF delivered every $20 \mathrm{sec}$ so that the time interval from the return of PTB or PTT to that of $T_{1}$ (the 1st response in TOF stimulation) was examined. Moreover, $20 \mathrm{sec}$ after the return of the $\mathrm{T}_{1}$, PTB or PTT stimulation was again applied to determine PTBC or PTC at the return of $T_{1}$.

All returns are expressed as number or mean \pm SD. Differences in patient characteristics in the four groups were analysed using analysis of variance (ANOVA) and Scheffe's test. The PTBC and PTC during recovery from neuromuscular blockade were compared using ANOVA 
TABLE I Demographic data (Number or mean \pm SD). PTBC = post-tetanic burst count; PTC = post-tetanic count; TOF = train-of-four. There were no differences in number of patients, age, sex, height, or body weight among the four groups.

\begin{tabular}{lllll}
\hline & PTBC & PTC & PTBC-TOF & PTC-TOF \\
\hline Number of patients & 15 & 15 & 15 & 15 \\
Age (yr) & $45.5 \pm 11.4$ & $45.0 \pm 9.5$ & $48.9 \pm 9.1$ & $45.4 \pm 8.4$ \\
Sex (M/F) & $7 / 8$ & $7 / 8$ & $7 / 8$ & $7 / 8$ \\
Height (cm) & $167.1 \pm 10.0$ & $166.9 \pm 10.2$ & $165.5 \pm 10.9$ & $165.9 \pm 11.4$ \\
Body weight (kg) & $56.7 \pm 6.9$ & $57.1 \pm 6.7$ & $56.0 \pm 7.0$ & $55.9 \pm 6.1$ \\
\hline
\end{tabular}

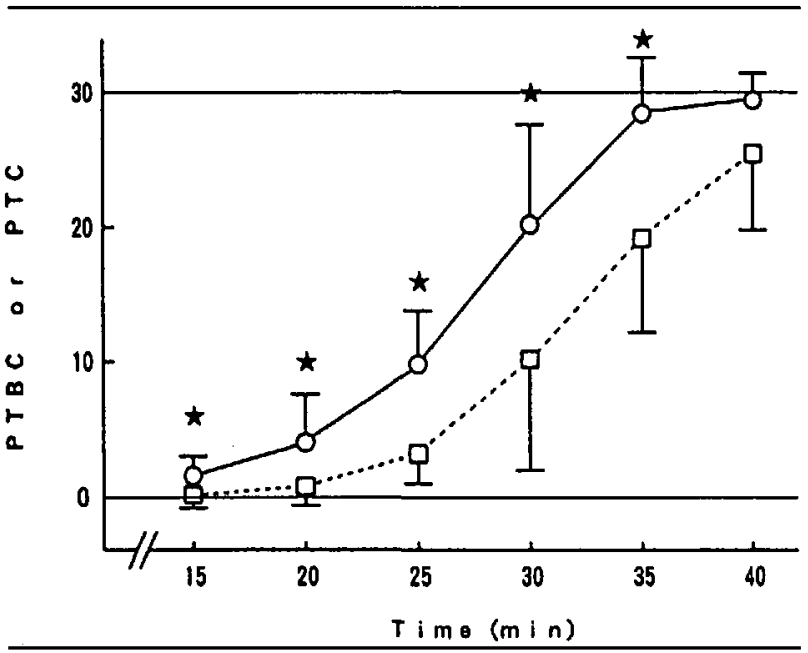

FIGURE Recoveries of post-tetanic burst count (PTBC) (O-O) and post-tetanic count (PTC) (D-..-D) after administration of vecuronium $0.07 \mathrm{mg} \cdot \mathrm{kg}^{-1}$. $\star$ Difference between PTBC and PTC $(P$ $<0.05$ ).

followed by unpaired $t$ test with Bonferroni's correction. Comparisons between times to the returns of PTB and PTT responses, between PTB- $T_{1}$ interval and PTT- , $_{1}$ interval, and between PTBC and PTC at the return of $T_{1}$ were made using unpaired $t$ test. Statistical significance was accepted when $P<0.05$. Statistical analyses were performed using a statistical package, STAT FLEX version 2 (Statview Inc., Tokyo, Japan) running on a desktop personal computer (NEC 9821 Ne, NEC Inc., Tokyo, Japan).

\section{Results}

Patient characteristics did not differ among groups (Table I). In no patient did the peripheral skin temperature decrease below $33^{\circ} \mathrm{C}$. The PTBC was greater than PTC during the 15-35 min after the administration of vecuronium $(P<0.05)$ (Figure). The time to return of PTB was less than that of PTT $(P=0.0005)$. Times to the returns of $T_{1}$ were not different between PTBC-TOF group and the PTC-TOF group. The PTB- $T_{1}$ interval was greater than the PTT- $T_{1}$ interval $(P=0.0003)$. At
TABLE II Time from administration of vecuronium $0.07 \mathrm{mg} \cdot \mathrm{kg}^{-1}$ to return of post-tetanic burst (PTB), post-tetanic twitch (PTT), or the first response in train-of-four (TOF) stimulation $\left(T_{1}\right)$; and relationship among PTB (or post-tetanic burst count (PTBC)), PTT (or posttetanic count (PTC)), and $T_{1}$. Results are expressed as \pm SD.

\begin{tabular}{llll}
\hline & $\begin{array}{l}\text { PTB or } \\
\text { PTBC }\end{array}$ & $\begin{array}{l}\text { PTT or } \\
\text { PTC }\end{array}$ & P value \\
\hline $\begin{array}{c}\text { Time from administration of } \\
\text { vecuronium to return of }\end{array}$ & & & \\
$\begin{array}{c}\text { PTB or PTT (min) } \\
\text { Time from administration of } \\
\text { vecuronium to return of } \mathrm{T}_{1} \\
\text { (min) }\end{array}$ & $17.7 \pm 3.2$ & $22.7 \pm 3.7$ & 0.0005 \\
$\begin{array}{c}\text { Time from return of PTB or } \\
\text { PTT to return of } \mathrm{T}_{1} \text { (min) }\end{array}$ & $13.3 \pm 2.6$ & $9.2 \pm 2.8$ & 0.0003 \\
PTBC or PTC at return of $\mathrm{T}_{1}$ & $14.3 \pm 6.9$ & $9.4 \pm 2.3$ & 0.0153 \\
\hline
\end{tabular}

the return of $T_{1}$, PTBC was greater than PTC $(P=$ 0.0153) (Table II).

\section{Discussion}

This study indicated that, using PTBC, more profound levels of neuromuscular blockade can be evaluated than by using PTC. In current practice a large dose of short or intermediate-acting neuromuscular relaxant is often administered so that such profound neuromuscular blockade subsides rapidly. Additionally, it has been reported that in some anaesthetised patients reflex movement can occur even when no response to PTT stimulation is observed during recovery from nondepolarising neuromuscular blockade. ${ }^{2,3}$ Therefore, precise timing of the incremental administration of neuromuscular relaxant should be ensured to maintain sufficient neuromuscular blockade. Hence, PTBC may play an important role in monitoring intense neuromuscular blockade because it can predict clinical recovery of neuromuscular blockade before PTC monitoring.

The response to burst stimulation is greater than that to single or train of four (TOF) stimulation. 4,5 Further, we have shown previously that the response to burst stimulation following tetanus, i.e., post-tetanic burst (PTB), appeared earlier than that to post-tetanic twitch (PTT) 
during recovery from vecuronium-induced neuromuscular blockade. ${ }^{1}$ Thus, using PTB, more profound neuromuscular blockade can be detected than when using PTT. However, even using PTB precise levels of intense neuromuscular blockade cannot be evaluated because the PTB which we reported previously produced, at most, only one muscular contraction following a tetanus. That is to say, using PTB, profound neuromuscular blockade can be divided into only two degrees, i.e., the presence or absence of muscular contraction in response to the PTB. This study showed that the time from vecuronium injection to return of PTB was more rapid than that of PTT and that PTBC was greater than PTC during the 15-35 $\mathrm{min}$ from the administration of vecuronium. Therefore, as intense neuromuscular blockade can be graded by the number of detectable contractions in response to the burst stimuli in PTBC, more profound levels of neuromuscular blockade can be classified according to the number of detectable muscular contraction than using the PTB which we reported previously.

In this study, the mean times from return of PTT to that of $T_{1}$, and mean PTC at the return of $T_{1}$ were 9.2 and $9.4 \mathrm{~min}$, respectively. These data are comparable with previous observations. ${ }^{6-8}$ On the other hand, this study demonstrated that the time from the return of PTB to that of $T_{1}$ was longer than PTT- $T_{1}$ interval (13.3 vs 9.2 $\mathrm{min}$ ), and that at the return of $\mathrm{T}_{1}$ PTBC was greater than PTC (14.3 vs 9.4). For that reason, using PTBC, return of the TOF response can be predicted earlier during recovery from neuromuscular blockade than when using PTC.

The present study was performed using succinylcholine to facilitate intubation. Twenty minutes after the previous administration of succinylcholine, vecuronium was given as the muscular relaxant. Nishizawa et al. ${ }^{9}$ showed that prior administration of succinylcholine did not affect the duration of action of vecuronium. On the contrary, Ono et al. ${ }^{10}$ demonstrated that $19.6 \mathrm{~min}$ after administration of succinylcholine, neuromuscular blockade returned completely, and at the full recovery from the succinylcholine-induced neuromuscular blockade twitch tension of the thumb returned to a level greater than its control. They also reported that the onset of the reduction in force produced by subsequent administration of vecuronium or pancuronium was faster and the recovery was slower, and this potentiating effect of succinylcholine persisted for at least two hours. In addition, d'Hollander et al. " noted that, after administration of succinylcholine, the duration of the action of vecuronium was prolonged, and this effect might be due to the affinity of acetylcholine receptors at the end-plates to subsequently administered nondepolarising neuromuscular relaxants. Therefore, in the present study, vecuronium- induced neuromuscular blockade might have been potentiated by the previous administration of succinylcholine.

It has been reported that tetanic stimuli applied too frequently affect subsequent neuromuscular responses. ${ }^{12,13}$ In this study, tetanic stimuli were administered every five minutes, and TOF stimuli were again applied one minute after the tetanic stimuli. It has also been noted that tetanic stimuli, given every five minutes, do not alter the recovery of subsequent neuromuscular responses, ${ }^{14}$ and that the tetanus-induced change of the subsequent TOF responses disappears within one minute. ${ }^{14,15}$ Hence, the tetanus-induced effect on the subsequent neuromuscular responses is of little importance.

In this study an acceleration transducer was used to evaluate the recovery of neuromuscular transmission. Silverman et al. ${ }^{16}$ reported that the accelograph displayed no response if the thumb contraction was less than $3 \%$ of control assessed using a force transducer. It was also demonstrated that, even when a force transducer was employed to measure the magnitude of muscular contraction, the minimum detectable level on the digital display was about 3 to $4 \%$ of its control twitch height so that one or two responses to TOF were often felt before any responses had been detected using a force transducer. ${ }^{17}$ Hence, if the times to return of PTB, PTT, and TOF responses had been measured by touch, the times to the return of neuromuscular reponses might have been shorter than those obtained in this study.

We conclude that, using PTBC, more profound and more detailed neuromuscular blockade can be evaluated than by using PTC. Thus, PTBC may be of help for monitoring intense neuromuscular blockade during clinical anaesthesia.

\section{References}

1 Saitoh Y, Toyooka H, Amaha $K$. Post-tetanic burst: a new monitoring method for intense neuromuscular block. $\mathrm{Br} \mathbf{J}$ Anaesth 1995; 74; 293-5.

2 Fernando PUE, Viby-Mogensen J, Bonsu AK, Tamilarasan A, Muchhal KK, Lamboume A. Relationship between posttetanic count and response to carinal stimulation during vecuronium-induced neuromuscular blockade. Acta Anaesthesiol Scand 1987; 31: 593-6.

3 Saitoh Y, Kaneda K, Toyooka H, Amaha K. Post-tetanic count and single twitch height at the onset of reflex movement after administration of vecuronium under different types of anaesthesia. Br J Anaesth 1994; 72: 688-90.

4 Saddler JM, Bevan JC, Donati F, Bevan DR, Pinto $S R$. Comparison of double-burst and train-of-four stimulation to assess neuromuscular blockade in children. Anesthesiology 1990; 73: 401-3.

5 Engbaek J, Ostergaard D, Viby-Mogensen J. Double burst stimulation (DBS): a new pattern of nerve stimulation to 
identify residual neuromuscular block. Br J Anaesth 1989; 62: 274-8.

6 Saitoh Y, Toyooka H, Amaha $K$. Relationship between post-tetanic twitch and single twitch response after administration of vecuronium. $\mathrm{Br} \mathrm{J}$ Anaesth 1993; 71: 443-4.

7 Toyooka H, Noguchi Y, Ebata T, Amaha $K$. A close relationship between post-tetanic twitch and train-of-four responses during neuromuscular blockade by vecuronium. J Anesth 1991; 5: 146-52.

8 Ridley SA, Braude N. Post-tetanic count and intense neuromuscular blockade with vecuronium in children. $\mathrm{Br} \mathrm{J}$ Anaesth 1988; 61: 551-6.

9 Nishizawa $M$, Goto $H$, Otagiri T, Nakajima K, Harashima $N$, Sakai J. Effect of prior administration of succinylcholine on duration of action of vecuronium during enflurane anaesthesia. Acta Anaesthesiol Scand 1994; 38: 380-3.

10 Ono K, Manabe N, Ohta Y, Morita K, Kasaka F. Influence of suxamethonium on the action of subsequently administered vecuronium or pancuronium. $\mathrm{Br} \mathrm{J}$ Anaesth 1989; 62: 324-6.

11 d'Hollander AA, Agoston S, De Ville A, Cuvelier F. Clinical and pharmacological actions of a bolus injection of suxamethonium: two phenomena of distinct duration. $\mathrm{Br} \mathbf{J}$ Anaesth 1983; 55: 131-4.

12 Feldman SA, Tyrrell MF. A new theory of the termination of action of the muscle relaxants. Proc Roy Soc Med 1970; 63: 692-5.

$13 \mathrm{Viby-Mogensen} \mathrm{J.}$ Clinical assessment of neuromuscular transmission. Br J Anaesth 1982; 54: 209-23.

14 Brull SJ, Connelly NR, O'Connor TZ, Silverman DG. Effect of tetanus on subsequent neuromuscular monitoring in patients receiving vecuronium. Anesthesiology 1991; 74: 64-70.

15 Saitoh Y, Masuda A, Toyooka H, Amaha K. Effect of tetanic stimulation on subsequent train-of-four responses at various levels of vecuronium-induced neuromuscular block. Br J Anaesth 1994; 73: 416-7.

16 Silverman DG, Connelly NR, O'Connor TZ, Garcia $R$, Brull SJ. Accelographic train-of-four at near threshold currents. Anesthesiology 1992; 76: 34-8.

17 Kirkegaard-Neilsen H, Helbo-Hansen HS, Severinsen IK, Lindholm P, Pedersen HS, Schmidt MB. Comparison of tactile and mechanomyographical assessment of response to double burst and train-of-four stimulation during moderate and profound neuromuscular blockade. Can J Anaesth 1995; 42: 21-7. 